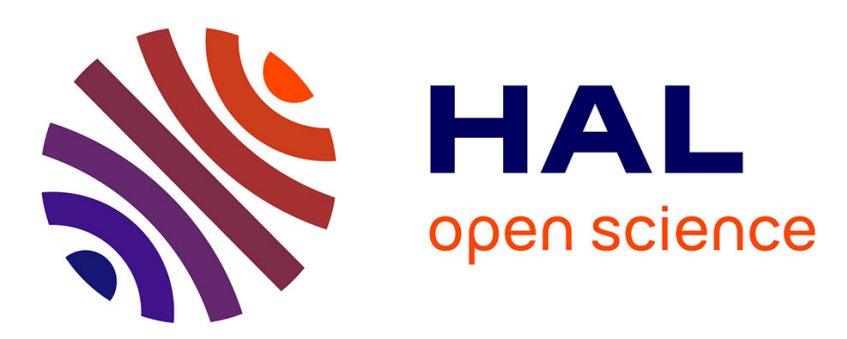

\title{
Light-Induced Spin State Switching in Copper(II)-Nitroxide-Based Molecular Magnet at Room Temperature
}

Xu-Dong Che, Maciej Lorenc, Evgeny V. Tretyakov, Victor I. Ovcharenko, Matvey V. Fedin

\section{To cite this version:}

Xu-Dong Che, Maciej Lorenc, Evgeny V. Tretyakov, Victor I. Ovcharenko, Matvey V. Fedin. LightInduced Spin State Switching in Copper(II)-Nitroxide-Based Molecular Magnet at Room Temperature. Journal of Physical Chemistry Letters, 2017, 8 (22), pp.5587-5592. 10.1021/acs.jpclett.7b02497 . hal01681159

HAL Id: hal-01681159

https://hal-univ-rennes1.archives-ouvertes.fr/hal-01681159

Submitted on 28 Feb 2018

HAL is a multi-disciplinary open access archive for the deposit and dissemination of scientific research documents, whether they are published or not. The documents may come from teaching and research institutions in France or abroad, or from public or private research centers.
L'archive ouverte pluridisciplinaire HAL, est destinée au dépôt et à la diffusion de documents scientifiques de niveau recherche, publiés ou non, émanant des établissements d'enseignement et de recherche français ou étrangers, des laboratoires publics ou privés. 


\title{
Light-Induced Spin State Switching in Copper(II)-Nitroxide Based Molecular Magnet at Room Temperature
}

\author{
$\mathrm{Xu}$ Dong, ${ }^{\mathrm{a}}$ Maciej Lorenc, ${ }^{\mathrm{a} a}$ Evgeny V. Tretyakov, ${ }^{\mathrm{b}, \mathrm{c}}$ Victor I. Ovcharenko, ${ }^{\mathrm{b}}$ Matvey V. Fedin ${ }^{\text {*b, }}$ \\ anstitut de Physique de Rennes, Universite Rennes 1, 35042 Rennes cedex, France \\ ${ }^{\mathrm{b}}$ International Tomography Center SB RAS, 630090, Novosibirsk, Russia \\ ${ }^{\mathrm{c}}$ Novosibirsk State University, 630090, Novosibirsk, Russia
}

\begin{abstract}
Molecular magnets $\mathrm{Cu}(\mathrm{hfac})_{2} \mathrm{~L}^{\mathrm{R}}$ exhibit an unusual type of photoinduced magnetostructural switching in exchange-coupled copper(II)-nitroxide clusters. Such photoswitching from stronglycoupled to weakly-coupled spin state (SS $\rightarrow$ WS) was recently found to be ultrafast, thus enhancing the interest in these systems and the scope of their potential applications. However, up to date such $\mathrm{SS} \rightarrow \mathrm{WS}$ photoswitching was demonstrated only at cryogenic temperatures, being limited by the absence of suitable SS states and short relaxation times at $T>100 \mathrm{~K}$. In this work we selected model compound $\mathrm{Cu}(\mathrm{hfac})_{2} \mathrm{~L}^{\text {iso-Pr }}$ residing in the mixed SS/WS state at room temperature and investigated it using femtosecond optical spectroscopy. Photoinduced spin dynamics was detected, and an ultrafast $\mathrm{SS} \rightarrow \mathrm{WS}$ photoswitching was for the first time demonstrated at room temperature, constituting an important milestone in the development of copper(II)-nitroxide molecular magnets for practical purposes.
\end{abstract}

\footnotetext{
*Corresponding authors: maciej.lorenc@univ-rennes1.fr (M.L.); mfedin@tomo.nsc.ru (M. V.F.)
} 
Design of switchable molecular materials is a dynamically developing field within materials science, where magneto-active compounds draw a particular attention due to the possibilities of using them in data processing/storage and other molecular spin devices. ${ }^{1-6}$ The latter type of compounds is largely represented by spin-crossover ( $\mathrm{SCO}$ ) complexes, which were actively investigated for a few past decades. ${ }^{5-27}$ The change of the spin state could be driven by a number of external stimuli including temperature, light, pressure, hard X-rays etc., among which light appears to be most practically useful and therefore impressive. The discovery of photoswitching and LightInduced Excited Spin State Trapping (LIESST) ${ }^{7}$ phenomenon in SCO compounds stimulated a huge amount of following studies, as well as intensive development of new types of photoswitchable molecules. ${ }^{3,8,10-13,28}$

Relatively recently the manifestations similar to LIESST were observed for principally different compounds. ${ }^{29-32}$ Copper(II)-nitroxide molecular magnets $\mathrm{Cu}(\mathrm{hfac})_{2} \mathrm{~L}^{\mathrm{R}}$ (where hfac=hexafluoroacetylacetonate and $\mathrm{L}^{\mathrm{R}}$ is a stable nitroxide radical) exhibit thermally-induced magnetostructural transitions between the so-called weakly-coupled spin state (WS) and stronglycoupled spin state (SS), which differ by geometry of metal coordination and the magnitude/sign of exchange interaction between metal and its ligand (Fig.1). In most cases, the low-temperature state is characterized by nitroxides occupying equatorial coordination positions of copper and strong antiferromagnetic exchange coupling (SS state), whereas the high-temperature state corresponds to the nitroxides in axial coordination positions (elongated Jahn-Teller axis of octahedron is flipped) and weak ferromagnetic exchange coupling (WS state). Unit cell volume in these compounds reversibly changes with temperature; therefore they are often called "breathing crystals". Irradiation with light allows switching of breathing crystals from SS to WS state, and such photoinduced WS state remains metastable at cryogenic temperatures on the time scale of hours. ${ }^{32}$ Various aspects of $\mathrm{SS} \rightarrow$ WS photoswitching and reverse WS $\rightarrow$ SS relaxation were investigated using Electron Paramagnetic Resonance (EPR) and steady-state Infrared Spectroscopy in a series of works. ${ }^{33-38}$ However, the information on kinetics and mechanism of the photoswitching could only be obtained recently using femtosecond optical spectroscopy ${ }^{39}$ That study, first of all, clearly demonstrated that photoswitching in breathing crystals is an ultrafast process occurring within available temporal resolution and takes $<50 \mathrm{fs}$. No signatures of the intermediate states upon intersystem crossing were detected, therefore it was generally proposed that photoswitching in $\mathrm{Cu}(\mathrm{hfac})_{2} \mathrm{~L}^{\mathrm{R}}$ family might be faster compared to SCO compounds because it is partly spin-allowed, ${ }^{39}$ even though a sub-50 fs photoswitching in SCO compound was demonstrated slightly later. ${ }^{40}$

Along with the shortening of time required for photoswitching, another appreciable improvement would be creating robust photoswitches functioning at room temperature. For SCO 

$\mathrm{Cu}(\mathrm{hfac})_{2} \mathrm{~L}^{\mathrm{R}}$ this task has not yet been achieved. One fundamental obstacle for this was the occurrence of thermal SS $\leftrightarrow$ WS transitions only at low temperatures, resulting in ground WS state for most of the compounds at room temperature, which excludes possibility of $\mathrm{SS} \rightarrow \mathrm{WS}$ photoswitching, while the reverse transition WS $\rightarrow$ SS was never reported in the breathing crystals. However, recently we demonstrated that SS $\rightarrow$ WS photoswitching can also be induced for the "thermally-unswitchable" breathing crystals, i.e. compounds exhibiting no or partial thermal switching to WS state in the whole range of their thermal stability. ${ }^{36}$ One of such compounds, $\mathrm{Cu}(\mathrm{hfac})_{2} \mathrm{~L}^{\text {iso-Pr }}$, was illuminated at cryogenic $(<20 \mathrm{~K})$ temperatures, resulting in observation of EPR spectra characteristic of photoinduced WS state. At $T>20 \mathrm{~K}$ the lifetime of this photoinduced state was shorter than temporal resolution of EPR (a few minutes in steady-state mode), therefore the photoswitching was not evidenced. However, it is fair to expect that for this and similar "thermallyunswitchable" compounds the photoswitching occurs even at room temperatures. Therefore, in the present work we have applied the femtosecond optical spectroscopy to this breathing crystal $\mathrm{Cu}(\mathrm{hfac})_{2} \mathrm{~L}^{\text {iso-Pr }}$ at room temperature, which allowed demonstrating for the first time the feasibility of ultrafast photoswitching in these compounds at ambient conditions.

The target compound $\mathrm{Cu}(\mathrm{hfac})_{2} \mathrm{~L}^{\text {iso-Pr }}$ was synthesized according to the previously developed procedures. ${ }^{43}$ To embed microcrystals in poly(vinyl chloride) (PVC) films, $1-2 \mathrm{mg}$ of each complex was dissolved in $1 \mathrm{~mL}$ of solution prepared from $1 \mathrm{~g}$ of a low molecular weight PVC and $200 \mathrm{~mL}$ of dichloroethane. This solution was equally sprayed onto a thin quartz plate to give a brown colored transparent film. Upon drying in ambient atmosphere for $24 \mathrm{~h}$, the film changed its color to blue that indicates a formation of microcrystal particles $(<30 \mu \mathrm{m})$ of target compound within PVC films. ${ }^{35,39}$ Prior to the optical measurements, the identity of the compound embedded in PVC film was verified by EPR. The details of the time-resolved optical experiments are provided in Supporting Information (SI) and elsewhere. ${ }^{44}$

Figure 1 sketches the structure of polymer chains of $\mathrm{Cu}(\mathrm{hfac})_{2} \mathrm{~L}^{\text {iso-Pr }}$ (Fig.1a) and shows the temperature dependence of its effective magnetic moment $\mu_{\mathrm{eff}}(T)$ (Fig.1b). The complete conversion of $\mathrm{Cu}(\mathrm{hfac})_{2} \mathrm{~L}^{\text {iso-Pr }}$ to WS state cannot be accomplished by temperature; however, as mentioned above, this transition can be successfully driven by light at low temperatures. ${ }^{36} \mathrm{UV}$-vis absorption spectra are typical of breathing crystals containing spin triads nitroxide-copper(II)-nitroxide and are dominated by intense bands of nitroxides (Fig.1c). In addition, a weaker band appears at low temperatures at $\sim 500 \mathrm{~nm}$ (shaded green), assigned to the metal-ligand charge transfer (MLCT) between nitroxide and copper, characteristic of SS state. ${ }^{34,35,39}$ In the case of $\mathrm{Cu}(\mathrm{hfac})_{2} \mathrm{~L}^{\text {iso-Pr }}$ this 
band is still distinguishable even at room temperature, because $\sim 50 \%$ of clusters still reside in the SS state (to be compared with pure WS state spectrum in Ref.39).
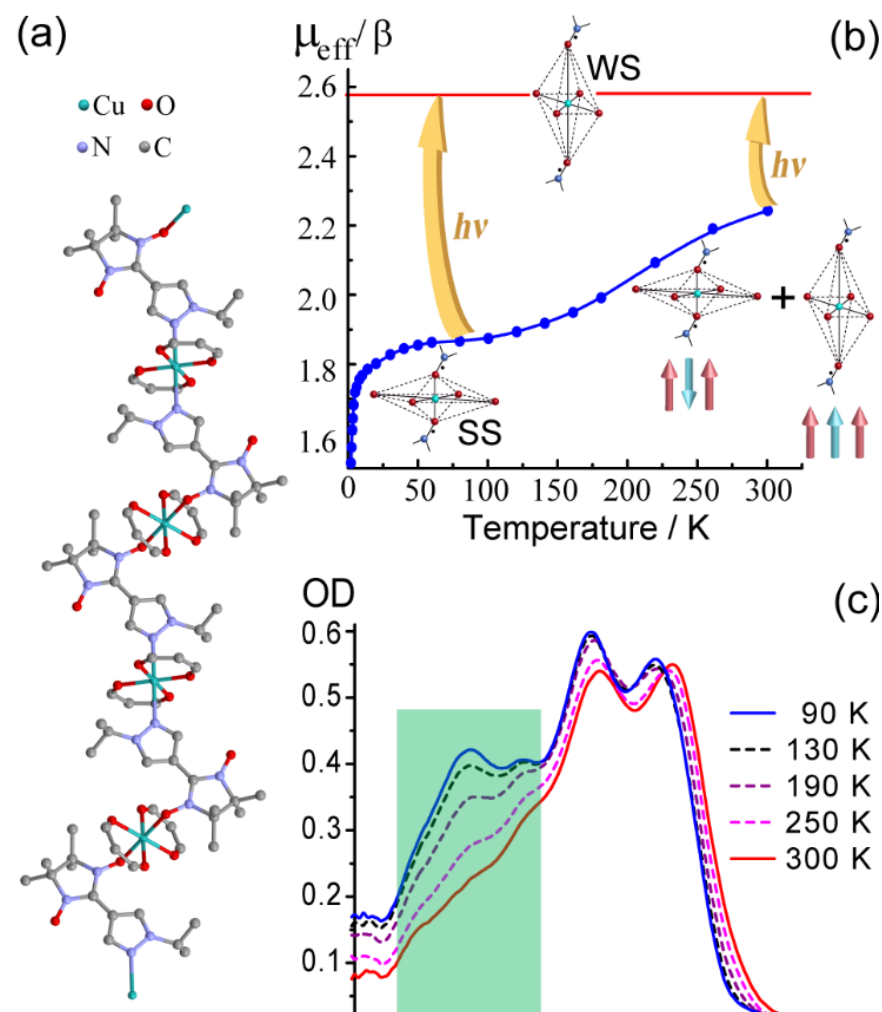

(b)

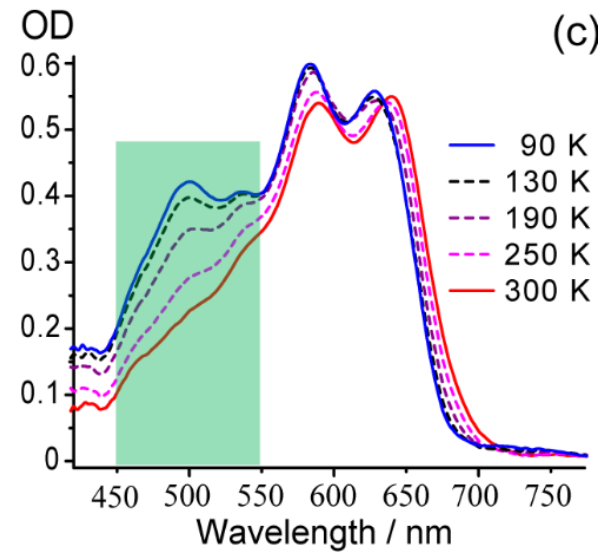

Figure 1. (a) Structure of polymer-chain complex $\mathrm{Cu}(\mathrm{hfac})_{2} \mathrm{~L}^{\text {iso-Pr }}$. (b) Temperature dependence of the effective magnetic moment $\left(\mu_{\text {eff }}\right)$ of $\mathrm{Cu}(\mathrm{hfac})_{2} \mathrm{~L}^{\text {iso-Pr }}$. Structures of SS and WS states are sketched, and corresponding arrangements of spins are shown using arrows. Yellow arrows illustrate the photoswitching to WS state, and horizontal red line - the magnetization level characteristic of WS state. (c) Temperature dependence of $\mathrm{UV}(\mathrm{vis})$ absorption spectrum of $\mathrm{Cu}(\mathrm{hfac})_{2} \mathrm{~L}^{\text {iso-Pr }}$. Spectral region of MLCT band is shaded with green.

In order to investigate the kinetics of photoswitching, we performed pump-probe timeresolved experiment by pumping the system at $675 \mathrm{~nm}$ and probing with white light (see SI for details). Remarkably, the signal at room temperature was readily detected (Fig. 2a), possibly evidencing the presence of photoinduced changes in the studied breathing crystal $\mathrm{Cu}(\mathrm{hfac})_{2} \mathrm{~L}^{\text {iso-Pr }}$. In general, the negative sign of the observed signal is consistent with previous observations of photoswitching at low temperatures (Ref. 39, and vide infra). However, the temporal evolution of the observed kinetics is more complicated compared to that obtained previously at low temperature for another breathing crystal. ${ }^{39}$ The kinetic trace, representative of many measurements series and shown in Fig.2a, is contributed by several processes developing at different time scales and yielding effects of different signs (see more kinetic traces and detailed description of fitting procedures in SI). Abrupt jump-down at sub-picosecond time (at $t \sim 0$ ) is followed by a slower decrease of the optical density (OD) with characteristic time of a few picoseconds; then the trend is reversed and 

simulated (Fig.2a, red) with two predominant contributions \#1 and \#2 (Fig.2b), which we are going to assign below.
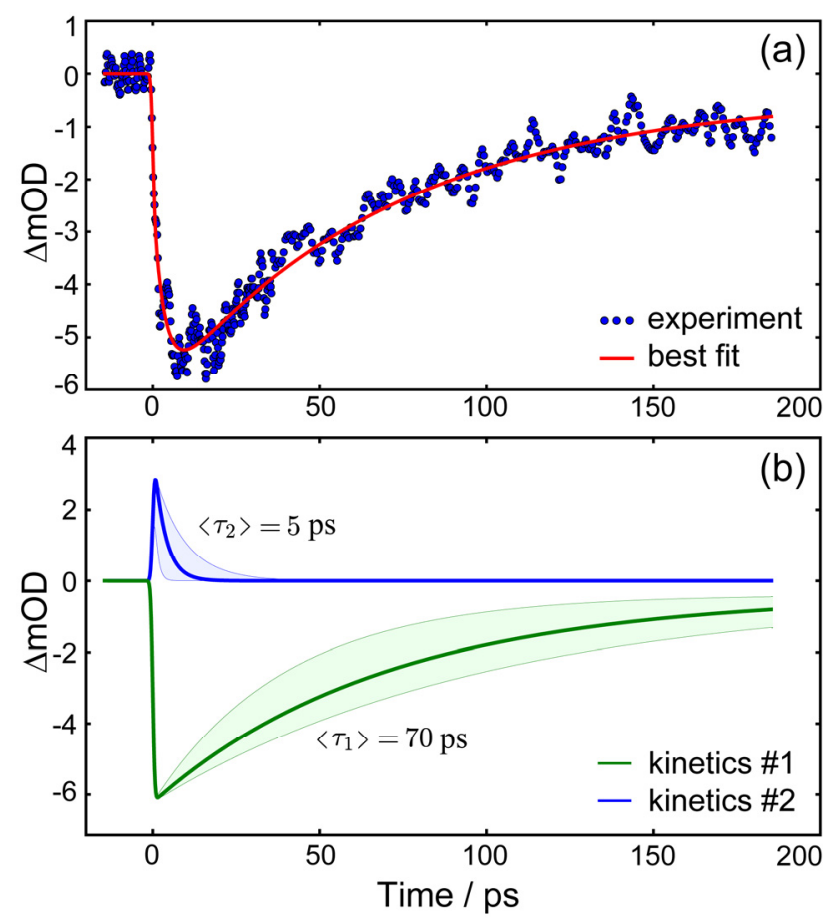

Figure 2. (a) Experimental kinetics $\Delta \operatorname{mOD}(t)$ observed in pump-probe experiment for $\mathrm{Cu}(\mathrm{hfac})_{2} \mathrm{~L}^{\text {iso-Pr }}$ at $300 \mathrm{~K}$ (black); mOD $=0.001 \cdot$ OD. Pumping was performed at $675 \mathrm{~nm}$, and probing with the white light integrated between 450-550 $\mathrm{nm}$ (see Fig.1c and SI for details). Red curve shows the simulation using the function $f(t)$ $=I R F^{*} h(t)$, where $h(t)=A_{1} \cdot \exp \left(-t / \tau_{1}\right)+A_{2} \cdot \exp \left(-t / \tau_{2}\right)+C,<\tau_{1}>=70 \mathrm{ps},<\tau_{2}>=5 \mathrm{ps}, \mathrm{C}=-0.00037 ; \mathrm{IRF}=$ instrument response function. (b) Deconvoluted contributions \#1 $\left(\mathrm{A}_{1} \cdot \exp \left(-t / \tau_{1}\right)\right)$ and $\# 2\left(\mathrm{~A}_{2} \cdot \exp \left(-t / \tau_{2}\right)\right)$. The shaded areas around deconvoluted kinetics illustrate the uncertainty due to $\mathrm{S} / \mathrm{N}$ accumulated over different samples (SI).

The major contribution \#1 consists of abrupt decrease of OD after the laser pulse and slow decay of this negative signal with the characteristic time $\left\langle\tau_{1}>=70\right.$ ps (determined with exponential fit). The smaller contribution \#2 ( $\approx 50 \%$ of \#1 by amplitude) exhibits an abrupt jump-up at subpicosecond time followed by exponential relaxation with the characteristic time $\left\langle\tau_{2}\right\rangle=5 \mathrm{ps}$. In addition, there is a small negative plateau reached by the kinetics at $t>180$ ps (see SI for details on fitting protocols). As an alternative to the model of two contributions (\#1 and \#2), the kinetic trace can also be reliably reproduced with two consecutive first-order reactions (ground state $\rightarrow$ intermediate state $\rightarrow$ final state), but the time-constant of 5 ps would imply an unusually long-lived intermediate in the photoexcitation scheme of breathing crystals. ${ }^{39}$ Spectral wise, the supposed intermediate would not have exactly the same absorbance as the ground- or the final- state, at least to the extent where its spectral intensity if not spectral shape would differ. Neither of such changes was observed on the picosecond timescale for a sibling compound. ${ }^{39}$ Furthermore, the relative 
weights of kinetics \#1 and kinetics \#2 varied between different parts of the film sample (see SI). The above arguments strongly support two independent processes assignable to the two species (vide infra and SI), rather than two states of one species, in the kinetic description of our results. In order to assign and interpret the contributions \#1 and \#2, we have performed a series of auxiliary benchmark measurements.
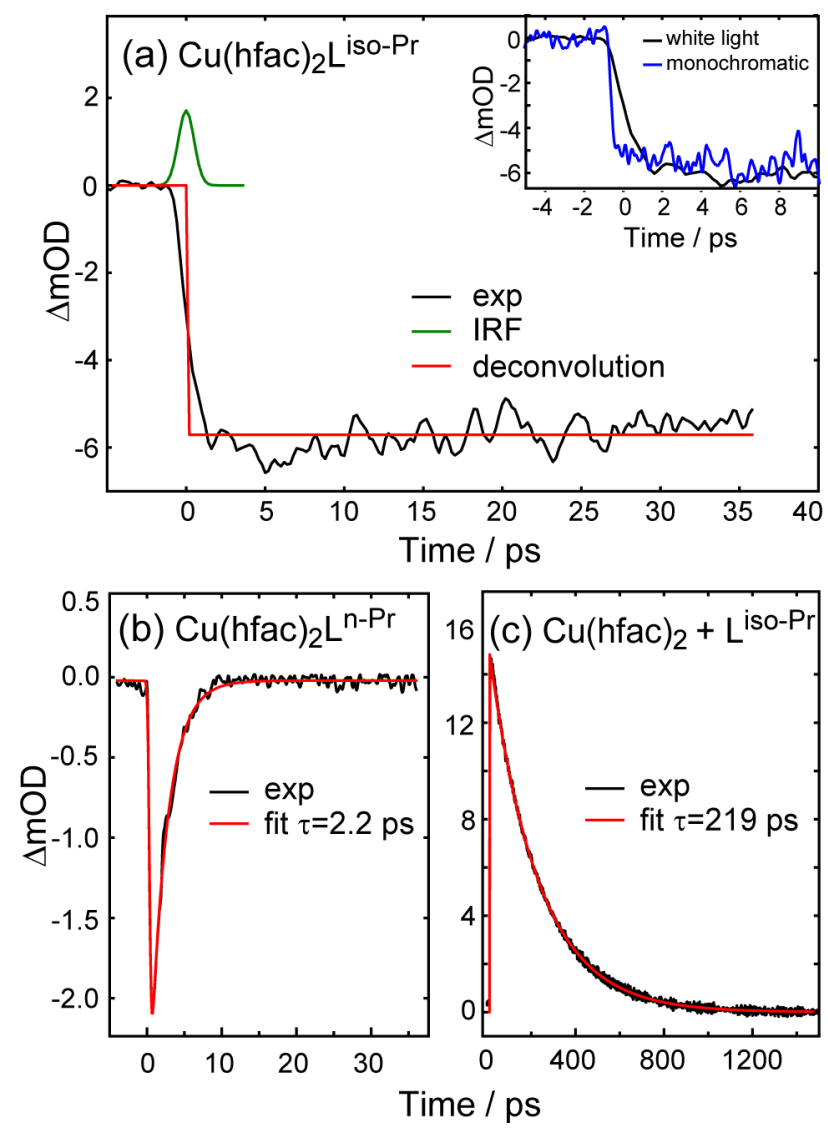

Figure 3. (a) Auxiliary pump-probe experiment on $\mathrm{Cu}(\mathrm{hfac})_{2} \mathrm{~L}^{\text {iso-Pr }}$ at $100 \mathrm{~K}$ with monochromatic pump at 675 $\mathrm{nm}$ and white light probe; the experimental kinetics (black) is deconvoluted into a step function (red) using pump probe Gaussian cross-correlation function (green, IRF=1.2 ps). The inset shows the same kinetics (black) compared with a monochromatic probe experiment (blue, IRF= $200 \mathrm{fs}$ ), pump unchanged; see SI for details. (b) Experimental kinetics of the sibling solid state compound $\mathrm{Cu}(\mathrm{hfac})_{2} \mathrm{~L}^{\mathrm{n}-\mathrm{Pr}}$ at ambient temperature. The fitted mono-exponential decay (red) has the time constant of 2.2 ps. (c) Experimental kinetics of the compound $\mathrm{Cu}(\mathrm{hfac})_{2} \mathrm{~L}^{\text {iso-Pr }}$ dissolved in acetone and measured at ambient temperature. The fitted monoexponential decay (red) has the time constant of $219 \mathrm{ps}$. In (b, c) the pump and probe wavelengths are $675 \mathrm{~nm}$ and $500 \mathrm{~nm}$, respectively.

Figure $3 \mathrm{a}$ shows the experimental kinetics $\Delta \mathrm{OD}(t)$ of $\mathrm{Cu}(\mathrm{hfac})_{2} \mathrm{~L}^{\text {iso-Pr }}$ measured at low temperature $100 \mathrm{~K}$, where the compound resides in pure ground SS state without any admixtures of WS state (see Fig.1b). The shape of the kinetics transforms into nearly pure stepwise jump-down, devoid of any additional processes (including fast relaxation), and closely resembles the previously observed photoswitching kinetics of the sibling compound $\mathrm{Cu}(\mathrm{hfac})_{2} \mathrm{~L}^{\mathrm{n}-\mathrm{Pr}}$ at $100 \mathrm{~K}^{39}$ Due to such remarkable similarity, this contribution, most clearly, corresponds to the SS $\rightarrow$ WS switching, which 
is (i) ultrafast (occurs within the temporal resolution of our setup) and (ii) has negative sign of $\Delta \mathrm{OD}(t)$ due to the smaller OD in WS state compared to SS state (see Fig.1c). Since there is no reason to expect a different excitation pathways between SS and WS states at room temperature and at $100 \mathrm{~K}$, we conclude that an abrupt decrease of the experimentally observed kinetics in Fig.2a is governed by the target SS $\rightarrow$ WS photoswitching, evidenced at room temperature for the first time; its deconvoluted contribution is shown in Fig. $2 \mathrm{~b}$ (kinetics \#1). The time scale of the SS $\rightarrow$ WS switching is shorter than the temporal resolution of the experiment, see the inset in Fig. 3a. Although we will not speculate on the nature of this initial process, being very likely the charge transfer from metal center to the nitroxide moieties with possible inter-system crossing, we can unambiguously conclude on its sub-200 fs timescale.

In addition to the $\mathrm{SS} \rightarrow \mathrm{WS}$ photoswitching in $\sim 1 / 2$ of spin triads having the ground SS state at room temperature, one might anticipate some signals arising from photoexcitation of the other $\sim 1 / 2$ of triads having the ground WS state (Figure 4 ). These triads might participate in processes of the type WS $\rightarrow \mathrm{WS}^{*} \rightarrow \mathrm{WS}$, where WS* is the excited state in WS coordination; such processes were previously studied using time-resolved EPR. ${ }^{35}$ To learn how these processes manifest themselves at room-temperature, we investigated the sibling compound $\mathrm{Cu}(\mathrm{hfac})_{2} \mathrm{~L}^{\mathrm{n}-\mathrm{Pr}}$ which fully resides in WS state at $T>250 \mathrm{~K}$ (see SI for details). The observed pure WS $\rightarrow$ WS $*$ WS kinetics for this compound is shown in Figure $3 \mathrm{~b}$. This kinetic has a negative going $\triangle \mathrm{OD}$ signal, and is characterized by an instantaneous buildup and a slower decay with time constant $\tau_{3} \sim 2.2$ ps. Since the compounds $\mathrm{Cu}(\mathrm{hfac})_{2} \mathrm{~L}^{\mathrm{n}-\mathrm{Pr}}$ and $\mathrm{Cu}(\mathrm{hfac})_{2} \mathrm{~L}^{\text {iso-Pr }}$ show very similar $\mathrm{WS} \rightarrow \mathrm{WS} * \rightarrow \mathrm{WS}$ kinetics at low temperature, ${ }^{35}$ one would not anticipate large differences in corresponding manifestations at room temperature. Therefore, we expect that characteristic decay time for this WS* $\rightarrow$ WS kinetics in $\mathrm{Cu}(\mathrm{hfac})_{2} \mathrm{~L}^{\text {iso-Pr }}$ is also in the few ps range at $300 \mathrm{~K}$. Thus, WS $\rightarrow$ WS $*$ WS process should contribute at short times $(<10 \mathrm{ps})$ to the observed kinetics in Fig. 2a. This contribution is not visible for the kinetics shown in Fig.2a, possibly due to the presence of competing positive-going kinetics (\#2 in Fig. 2b) of different origin, not related to SS $\rightarrow$ WS transition (see below and SI for details).

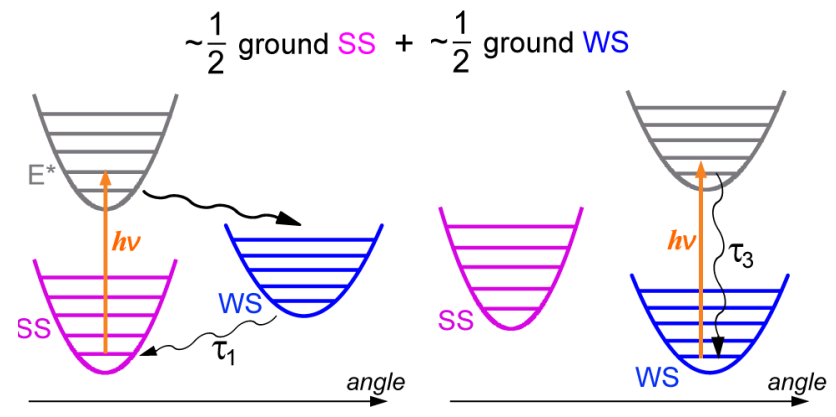

Figure 4. Energy schemes of $\mathrm{Cu}(\mathrm{hfac})_{2} \mathrm{~L}^{\text {iso-Pr }}$ at $300 \mathrm{~K}$ residing in $\sim 50 \%$ of ground $\mathrm{SS}$ states (left) and $\sim 50 \%$ ground WS states (right). Corresponding photoexcitation, switching and relaxation processes are shown. 


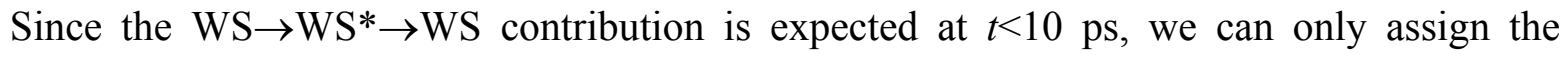
observed slow ( $\sim 70 \mathrm{ps})$ decay in $\mathrm{Cu}(\mathrm{hfac})_{2} \mathrm{~L}^{\text {iso-Pr }}$ to a structural relaxation from photoinduced WS to the ground SS states. The timescale of this relaxation curve corresponds well to the expectations. Such WS $\rightarrow$ SS relaxation occurs on the scale of hours at $T<20 \mathrm{~K}$, but speeds up to $\sim 100 \mu$ s $(\sim 7$ orders of magnitude) at $T=90 \mathrm{~K},{ }^{39}$ therefore further acceleration by $\sim 6$ orders of magnitude at $T=300 \mathrm{~K}$ up to $\approx 70$ ps seems plausible. We have previously shown that structural WS $\rightarrow \mathrm{SS}$ relaxation at low temperatures is self-decelerating in both $\mathrm{Cu}(\mathrm{hfac})_{2} \mathrm{~L}^{\text {iso-Pr }}$ and $\mathrm{Cu}(\mathrm{hfac})_{2} \mathrm{~L}^{\mathrm{n}-\mathrm{Pr}}$ compounds, being governed by a broad Gaussian distribution $\left(\sigma \sim 20-40 \mathrm{~cm}^{-1}\right)$ of the energy barrier between WS and SS state potential wells. ${ }^{33,36}$ The relaxation curves observed at low temperatures begin with the rapid decay and then gradually slow down nearly to the plateaus. However, since the dispersion of relaxation rates is governed by the Arrhenius law $\Delta k \sim \exp (-\sigma / k T)$, one would not expect large effect for $\sigma<<k T$, which is the case at $300 \mathrm{~K}$. Therefore, the anticipated shape of the relaxation kinetics at room temperature should not noticeably deviate from the mono-exponential. Thus, the small plateau distinguishable at long time delays most likely owes to the local heating effects. Indeed, upon photoexciation the compound should reach thermal homogeneity on the subnanosecond timescale, ${ }^{45}$ while the SS/WS fractions settle to equilibrium at an increased temperature on a time scale determined by the energy barrier between SS and WS states and this temperature. ${ }^{46}$ At room temperature, such equilibration process will proceed significantly faster, on the nanosecond time-scale, as was evidenced by a temperature jump study. ${ }^{47}$ We can therefore argue that the weak plateau following WS to SS relaxation is the signature of thermal population of WS state. While further investigations at markedly different temperatures and on much longer timescales would be required to unequivocally pin down the origin of the plateau, they are well beyond the foci of the current paper.

Finally, the contribution \#2 (Fig.2b) with positive $\Delta \mathrm{OD}$ needs to be explained. Since both $\mathrm{SS} \rightarrow \mathrm{WS} \rightarrow \mathrm{SS}$ and $\mathrm{WS} \rightarrow \mathrm{WS}^{*} \rightarrow \mathrm{WS}$ have negative $\Delta \mathrm{OD}$, the small positive going contribution is likely to arise from admixtures of uncomplexed species $\mathrm{Cu}(\mathrm{hfac})_{2}$ and $\mathrm{L}^{\text {iso-Pr }}$, which are present in the polymer film along with microcrystals in concentration $<10 \% .{ }^{38}$ In order to determine the sign of the corresponding kinetics, we have dissolved $\mathrm{Cu}(\mathrm{hfac})_{2} \mathrm{~L}^{\text {iso-Pr }}$ in acetone, where it exists as a mixture of $\mathrm{Cu}(\mathrm{hfac})_{2}$ and free radical ligand $\mathrm{L}^{\text {iso-Pr }}$, and measured as such at room temperature (Figure 3c and SI). Indeed, the obtained kinetics has a positive $\Delta \mathrm{OD}$; however, the decay time of this kinetics is $\sim 2$ orders of magnitude longer than positive contribution observed in the polymer film. We tentatively attribute this difference to a greater number of channels for energy release, 
typically lattice phonon modes, available at solid state. At low temperatures, this contribution becomes negligible by amplitude due to a largely predominant contribution of $\mathrm{SS} \rightarrow \mathrm{WS} \rightarrow \mathrm{SS}$ process and, possibly, drastic prolongation of the relaxation times leading to saturation of these signals. Thus, the small positive contribution \#2 most likely arises from admixtures of uncomplexed species, whose contribution does not enter into the kinetic scheme of SS $\rightarrow$ WS transition.

In summary, the observed photoinduced kinetics of $\mathrm{Cu}(\mathrm{hfac})_{2} \mathrm{~L}^{\text {iso-Pr }}$ at room temperature is dominated by SS $\rightarrow$ WS photoswitching in $\sim 1 / 2$ of spin triads occurring within the first $\sim 200 \mathrm{fs}$ after the laser pulse, and following WS $\rightarrow$ SS relaxation with the time constant $\sim 70$ ps (\#1). The effect of photoexcitation of the other $\sim 1 / 2$ of spin triads in the ground WS state, i.e. the WS $\rightarrow$ WS $\rightarrow$ WS process, occurs within first $\sim 10 \mathrm{ps}$; it has a smaller amplitude and temporally coincides with contribution from impurity (uncomplexed species that gives opposite sign of $\Delta \mathrm{OD}$ ) in the film (\#2). The contribution of WS $\rightarrow$ WS $\rightarrow$ WS process might be totally eliminated in the future by designing breathing crystals whose thermal transition temperature is shifted to higher than room temperature. Currently, a significant progress was achieved in this direction, ${ }^{48}$ yet with still partial population of unwanted WS states at room temperature. In order to exclude totally the presence of impurities arising from uncomplexed species in the film, one needs to optimize synthetic protocols and obtain more pure materials; before present studies, it was not realized that the presence of such impurities contributes to the fs kinetics at room temperatures. We admit that the exhaustive interpretation of contributions from uncomplexed species and WS $\rightarrow \mathrm{WS}^{*} \rightarrow \mathrm{WS}$ processes is not accomplished in the present work; however, from practical point of view, these are unwanted contributions and should be eliminated synthetically in the future.

Most importantly, this study for the first time evidenced the feasibility of photoswitching in nitroxide-copper(II)-nitroxide molecular magnets at room temperature. The switching occurs within less than $200 \mathrm{fs}$, whereas the lifetime of the excited (WS) state is at least three orders of magnitude longer (on the order of $100 \mathrm{ps}$ ), thus allowing numerous spin switching operations to be accomplished. There is no real trapping of this excited spin state in contrast to low temperatures; however, principal feasibility of such photoinduced magnetostructural transitions is highly important for designing photomagnetic switches. As next steps of this research, we foresee a design of breathing crystals whose ground state at room temperature is a pure SS state, and a design of compounds exhibiting thermal hysteresis around room temperature. Both directions require thorough synthetic efforts, which are now justified by the first observation of photoswitching in this family at room temperatures. 


\section{Acknowledgements}

This work was supported by FASO Russia (project 0333-2016-0001) and ANR-16-CE30-0018.

\section{References}

(1) Gütlich, P.; Goodwin, H. A. Spin Crossover in Transition Metal Compounds. Top. Curr. Chem. 2004, 233-235.

(2) Rocha, A. R.; Garcia-Suarez, V. M.; Bailey, S. W.; Lambert, C. J.; Ferrer, J.; Sanvito, S. Towards Molecular Spintronics. Nat. Mater. 2005, 4, 335-339.

(3) Sato, O.; Tao, J.; Zhang, Y. Z. Control of Magnetic Properties Through External Stimuli. Angew. Chem. Int. Ed. 2007, 46, 2152-2187.

(4) Bogani, L.; Wernsdorfer, W. Molecular Spintronics Using Single-Molecule Magnets. Nat. Mater. 2008, 7, 179-186.

(5) Halcrow, M. A. Spin-Crossover Materials: Properties and Applications, John Wiley \& Sons, 2013.

(6) Manrique-Juárez, M. D.; Rat, S.; Salmon, L.; Molnár, G.; Quintero, C. M.; Nicu, L.; Shepherd, H. J.; Bousseksou, A. Switchable Molecule-Based Materials for Micro- and Nanoscale Actuating Applications: Achievements and Prospects. Coord. Chem. Rev. 2016, 308, 395-408.

(7) Decurtins, S.; Gutlich, P.; Kohler, C. P.; Spiering, H.; Hauser, A. Light-Induced Excited Spin State Trapping in a Transition-Metal Complex - the Hexa-1-Propyltetrazole-Iron (Ii) Tetrafluoroborate Spin-Crossover System. Chem. Phys. Lett., 1984, 105, 1-4.

(8) Hauser, A. Light-Induced Spin Crossover and the High-Spin -> Low-Spin Relaxation. Top. Curr. Chem. 2004, 234, 155-198.

(9) Gutlich, P; Gaspar, AB; Garcia, Y. Spin State Switching in Iron Coordination Compounds. Belstein J. Org. Chem. 2013, 9, 342-391.

(10) Letard, J.-F. Photomagnetism of Iron(II) Spin Crossover Complexes - the T(LIESST) Approach. J. Mater. Sci. 2006, 16, 2550-2559.

(11) Vanko, G; Renz, F; Molnar, G; Neisius, T; Karpati, S. Hard-X-ray-Induced Excited-Spin-State Trapping. Angew. Chem. Int. Ed. 2007, 46, 5306-5309.

(12) Bousseksou, A.; Molnar, G.; Salmon, L.; Nicolazzi, W. Molecular Spin Crossover Phenomenon: Recent Achievements and Prospects. Chem. Soc. Rev. 2011, 40, 3313-3335.

(13) Warner, B.; Oberg, J. C.; Gill, T. G.; El Hallak, F.; Hirjibehedin, C. F.; Serri, M.; Heutz, S.; Arrio, M. A.; Sainctavit, P.; Mannini, M.; Poneti, G.; Sessoli, R.; Rosa, P. Temperature- and Light-Induced Spin Crossover Observed by X-ray Spectroscopy on Isolated Fe(II) Complexes on Gold. J. Phys. Chem. Lett. 2013, 4, 1546-1552.

(14) Novikov, V. V.; Ananyev, I. V.; Pavlov, A. A.; Fedin, M. V.; Lyssenko, K. A.; Voloshin, Y. Z. Spin-Crossover Anticooperativity Induced by Weak Intermolecular Interactions. J. Phys. Chem. Lett. 2014, 5, 496-500.

(15) Pinkowicz, D.; Rams, M.; Misek, M.; Kamenev, K. V.; Tomkowiak, H.; Katrusiak, A.; Sieklucka, B. Enforcing Multifunctionality: A Pressure-Induced Spin-Crossover Photomagnet. J. Am. Chem. Soc. 2015, 137, 8795-8802. 
(16) Gomez, V.; de Pipaon, C. S.; Maldonado-Illescas, P.; Waerenborgh, J. C.; Martin, E.; Benet-Buchholz, J.; GalanMascaros, J. R. Easy Excited-State Trapping and Record High T-TIESST in a Spin-Crossover Polyanionic Fe-II Trimer. J. Am. Chem. Soc. 2015, 137, 11924-11927.

(17) Rosner, B; Milek, M; Witt, A; Gobaut, B; Torelli, P; Fink, R. H.; Khusniyarov, M. M. Reversible Photoswitching of a Spin-Crossover Molecular Complex in the Solid State at Room Temperature. Angew. Chem. Int. Ed. 2015, 54, 12976-12980.

(18) Klinduhov, N.; Boukheddaden, K. Vibronic Theory of Ultrafast Intersystem Crossing Dynamics in a Single SpinCrossover Molecule at Finite Temperature beyond the Born Oppenheimer Approximation. J. Phys. Chem. Lett. 2016, 7, $722-727$.

(19) Sagar, D. M.; Baddour, F. G.; Konold, P.; Ullom, J.; Ruddy, D. A.; Johnson, J. C.; Jimenez, R. Femtosecond Measurements of Size-Dependent Spin Crossover in Fe-II(pyz) Pt(CN)(4) Nanocrystals. J. Phys. Chem. Lett. 2016, 7, $148-153$

(20) Konarev, D. V.; Khasanov, S. S.; Shestakov, A. F.; Ishikawa, M.; Otsuka, A.; Yamochi, H.; Saito, G.; Lyubovskaya, R. N. Spin Crossover in Anionic Cobalt-Bridged Fullerene (Bu4N+) $\{\mathrm{Co}(\mathrm{Ph} 3 \mathrm{P})\}(2)(\mathrm{mu}(2)-\mathrm{Cl}-)(\mathrm{mu}(2)-$ eta(2),eta(2)-C-60)(2) Dimers. J. Am. Chem. Soc. 2016, 138, 16592-16595.

(21) Sy, M.; Garrot, D.; Slimani, A.; Paez-Espejo, M.; Varret, F.; Boukheddaden, K. Reversible Control by Light of the High-Spin Low-Spin Elastic Interface inside the Bistable Region of a Robust Spin-Transition Single Crystal. Angew. Chem. Int. Ed. 2016, 55, 1755-1759.

(22) Wang, Y. G.; Zhou, Z. Y.; Wen, T.; Zhou, Y. N.; Li, N.; Han, F.; Xiao, Y. M.; Chow, P.; Sung, J. L.; Pravica, M.; Cornelius, A. L.; Yang, W. G.; Zhao, Y. S. Pressure-Driven Cooperative Spin-Crossover, Large-Volume Collapse, and Semiconductor-to-Metal Transition in Manganese(II) Honeycomb Lattices. J. Am. Chem. Soc. 2016, 138, $15751-15757$.

(23) Travieso-Puente, R.; Broekman, J. O. P.; Chang, M. C.; Demeshko, S.; Meyer, F.; Otten, E. Spin-Crossover in a Pseudo-tetrahedral Bis(formazanate) Iron Complex. J. Am. Chem. Soc. 2016, 138, 5503-5506.

(24) Paez-Espejo, M.; Sy, M.; Boukheddaden, K.Elastic Frustration Causing Two-Step and Multistep Transitions in Spin-Crossover Solids: Emergence of Complex Antiferroelastic Structures. J. Am. Chem. Soc. 2016, 138, $3202-3210$.

(25) Diaconu, A; Lupu, S. L.; Rusu, I.; Risca, I. M.; Salmon, L.; Molnar, G.; Bousseksou, A.; Demont, P.; Rotaru, A. Piezoresistive Effect in the [Fe(Htrz)(2)(trz)](BF4) Spin Crossover Complex. J. Phys. Chem. Lett. 2017, 8, 3147-3151.

(26) Jiang, Y. F.; Liu, L. C.; Muller-Werkmeister, H. M.; Lu, C.; Zhang, D. F.; Field, R. L.; Sarracini, A.; Moriena, G.; Collet, E.; Miller, R. J. D. Structural Dynamics upon Photoexcitation in a Spin Crossover Crystal Probed with Femtosecond Electron Diffraction. Angew. Chem. Int. Ed. 2017, 56, 7130-7134.

(27) Wang, H. Y.; Ge, J. Y.; Hua, C.; Jiao, C. Q.; Wu, Y.; Leong, C. F.; D'Alessandro, D. M.; Liu, T.; Zuo, J. L. Photoand Electronically Switchable Spin-Crossover Iron(II) Metal-Organic Frameworks Based on a Etrathiafulvalene Ligand. Angew. Chem. Int. Ed. 2017, 56, 5465-5470.

(28) Carbonera, C.; Dei, A.; Letard, J.-F.; Sangregorio, C.; Sorace, L. Relaxation Dynamics of a Photoinduced Dicobalt-tetraoxolene Valence Tautomer, Inorg. Chim. Acta, 2007, 360, 3825-3828.

(29) Ovcharenko, V. I.; Fokin, S. V.; Romanenko, G. V.; Ikorskii, V. N.; Tretyakov, E. V.; Vasilevsky, S. F.; Sagdeev, R. Z. Unusual Spin Transitions. Mol. Phys. 2002, 100, 1107-1115.

(30) Ovcharenko, V.; Bagryanskaya, E. Spin-Crossover Materials: Properties and Applications, 2013, pp. $239-280$.

(31) Fedin, M. V.; Veber, S. L.; Bagryanskaya, E. G.; Ovcharenko, V. I. Electron Paramagnetic Resonance of Switchable Copper-Nitroxide-Based Molecular Magnets: an Indispensable Tool for Intriguing Systems. Coord. Chem. Rev. 2015, 289-290, 341-356.

(32) Fedin, M.; Ovcharenko, V.; Sagdeev, R.; Reijerse, E.; Lubitz, W.; Bagryanskaya, E. Light-Induced Excited Spin State Trapping in an Exchange-Coupled Nitroxide-Copper(II)-Nitroxide Cluster. Angew. Chem. Int. Ed. 2008, 47, 68976899.

(33) Fedin, M. V.; Maryunina, K. Y.; Sagdeev, R. Z.; Ovcharenko, V. I.; Bagryanskaya, E. G. Self-Decelerating Relaxation of the Light-Induced Spin States in Molecular Magnets Cu(hfac)2LR Studied by Electron Paramagnetic Resonance. Inorg. Chem. 2012, 51, 709-717.

(34) Drozdyuk, I. Yu.; Tolstikov, S. E.; Tretyakov, E. V.; Veber, S. L.; Ovcharenko, V. I.; Sagdeev, R. Z.; Bagryanskaya, E. G.; Fedin, M. V. Light-Induced Magnetostructural Anomalies in a Polymer Chain Complex of $\mathrm{Cu}$ (hfac)2 with tert-Butylpyrazolylnitroxides. J. Phys. Chem. A 2013, 117, 6483-6488. 
(35) Fedin, M. V.; Bagryanskaya, E. G.; Matsuoka, H.; Yamauchi, S.; Veber, S. L.; Maryunina, K. Y.; Tretyakov, E. V.; Ovcharenko, V. I.; Sagdeev, R. Z. W-Band Time-Resolved Electron Paramagnetic Resonance Study of LightInduced Spin Dynamics in Copper-Nitroxide-Based Switchable Molecular Magnets. J. Am. Chem. Soc. 2012, 134, 16319-16326.

(36) Barskaya, I. Yu.; Tretyakov, E. V.; Sagdeev, R. Z.; Ovcharenko, V. I.; Bagryanskaya, E. G.; Maryunina, K. Y.; Takui, T.; Sato, K.; Fedin, M. V. Photoswitching of a Thermally Unswitchable Molecular Magnet Cu(hfac)2Li-Pr Evidenced by Steady-State and Time-Resolved Electron Paramagnetic Resonance. J. Am. Chem. Soc. 2014, 136, 1013210138.

(37) Veber, S. L.; Suturina, E. A.; Fedin, M. V.; Boldyrev, K. N.; Maryunina, K. Y.; Sagdeev, R. Z.; Ovcharenko, V. I.; Gritsan, N. P.; Bagryanskaya, E. G. FTIR Study of Thermally Induced Magnetostructural Transitions in Breathing Crystals. Inorg. Chem. 2015, 54, 3446-3455.

(38) Barskaya, I. Yu.; Veber, S. L.; Fokin, S. V.; Tretyakov, E. V.; Bagryanskaya, E. G.; Ovcharenko, V. I.; Fedin, M. V. Structural Specifics of Light-Induced Metastable States in Copper(II)-Nitroxide Molecular Magnets. Dalton Trans. 2015, 44, 20883-20888.

(39) Kaszub, W.; Marino, A.; Lorenc, M.; Collet, E.; Bagryanskaya, E. G.; Tretyakov, E. V.; Ovcharenko, V. I.; Fedin, M. V. Ultrafast Photoswitching in a Copper-Nitroxide-Based Molecular Magnet. Angew. Chem. Int. Ed., 2014, 53, 10636-10640.

(40) Auboeck, G.; Chergui, M. Sub-50-fs Photoinduced Spin Crossover in $[\mathrm{Fe}(\mathrm{bpy})(3)](2+)$. Nature Chem. 2015, 7 , 629-633.

(41) Bonhommeau, S.; Molnar, G.; Galet, A.; Zwick, A.; Real, J. A.; McGarvey, J. J.; Bousseksou, A. One Shot Laser Pulse Induced Reversible Spin Transition in the Spin-Crossover Complex [Fe(C4H4N2]\{Pt(CN)4\}] at Room Temperature. Angew. Chem. Int. Ed. 2005, 44, 4069-4073.

(42) Cobo, S.; Ostrovskii, D.; Bonhommeau, S.; Vendier, L.; Molnar, G.; Salmon, L.; Tanaka, K.; Bousseksou, A. Single-laser-shot-induced Complete Bidirectional Spin Transition at Room Temperature in Single Crystals of $\mathrm{Fe}^{\mathrm{II}}$ (pyrazine) $\mathrm{Pt}(\mathrm{CN})_{4}$. J. Am. Chem. Soc. 2008, 130, 9019-9024.

(43) Ovcharenko, V. I.; Fokin, S. V.; Romanenko, G. V.; Shvedenkov, Yu. G.; Ikorskii, V. N.; Tretyakov, E. V.; Vasilevskii, S. F.. Nonclassical Spin Transitions. J. Struct. Chem. 2002, 43, 153-167.

(44) D’Amico, C.; Lorenc, M.; Collet, E.; Green, K. A.; Costuas, K.; Mongin, O.; Blanchard-Desce, M.; Paul, F. Probing Charge-Transfer Excited States in a Quasi-Nonluminescent Electron-Rich Fe(II)-Acetylide Complex by Femtosecond Optical Spectroscopy. J. Phys. Chem. C 2012, 116, 3719-3727.

(45) Cammarata, M.; Lorenc, M.; Kim, T. K.; Lee, J. H.; Kong, Q. Y.; Pontecorvo, E.; Lo Russo, M.; Schiró, G.; Cupane, A.; Wulff, M.; Ihee, H. Impulsive Solvent Heating Probed by Picosecond X-ray Diffraction. J. Chem. Phys. 2006, 124, 124504.

(46) Lorenc, M.; Balde, Ch.; Kaszub, W.; Tissot, A.; Moisan, N.; Servol, M.; Buron-Le Cointe, M.; Cailleau, H.; Chasle, P.; Czarnecki, P.; Boillot, M. L.; Collet, E. Cascading photoinduced, elastic, and thermal switching of Spin States Triggered by a Femtosecond Laser Pulse in an Fe(III) Molecular Crystal. Phys. Rev. B 2012, 85, 054302.

(47) Dose, E. V.; Hoselton, M. A.; Sutin, N.; Tweedle, M. F.; Wilson, L. J.. Dynamics of Intersystem Crossing Processes in Solution for Six-Coordinate d5, d6, and d7 Spin-Equilibrium Metal Complexes of Iron(III), Iron(II), and Cobalt(II). J. Am. Chem. Soc. 1978, 100, 1141-1147.

(48) Tolstikov, S. E.; Artiukhova, N. A.; Romanenko, G. V.; Bogomyakov, A. S.; Zueva, E. M.; Barskaya, I. Yu.; Fedin, M. V.; Maryunina, K. Yu.; Tretyakov, E. V.; Sagdeev, R. Z.; Ovcharenko, V. I. Heterospin Complex Showing Spin Transition at Room Temperature. Polyhedron 2015, 100, 132-138. 


\section{Page 13 of 18}

Table of Contents Graphic

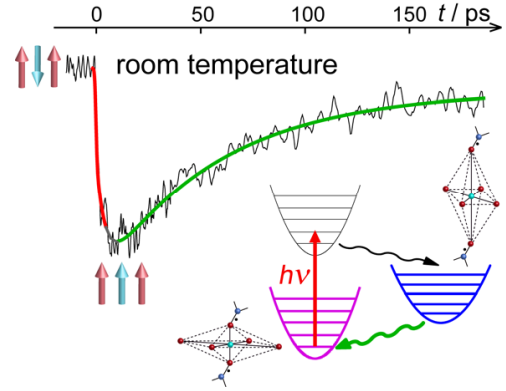




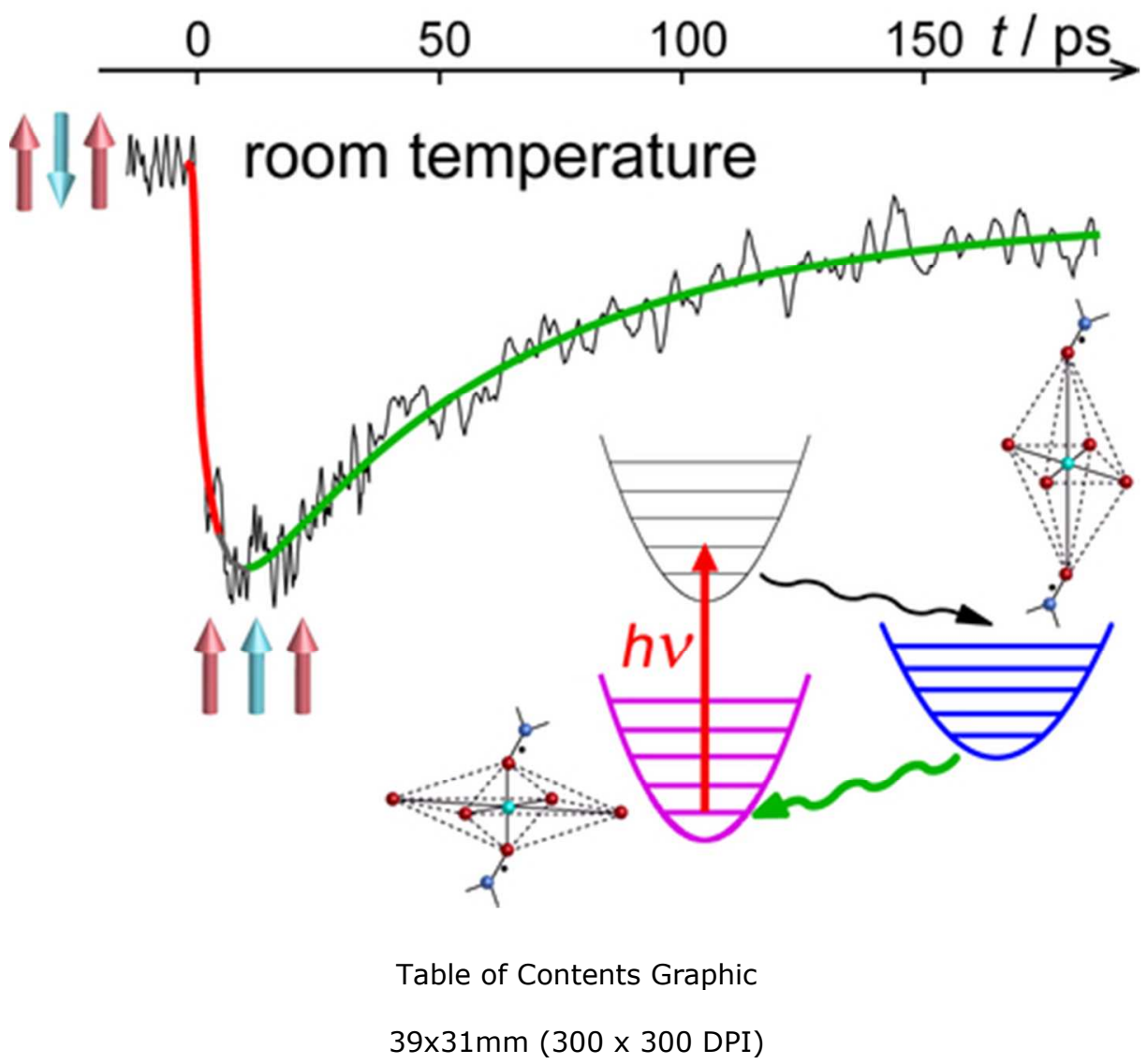


(a)
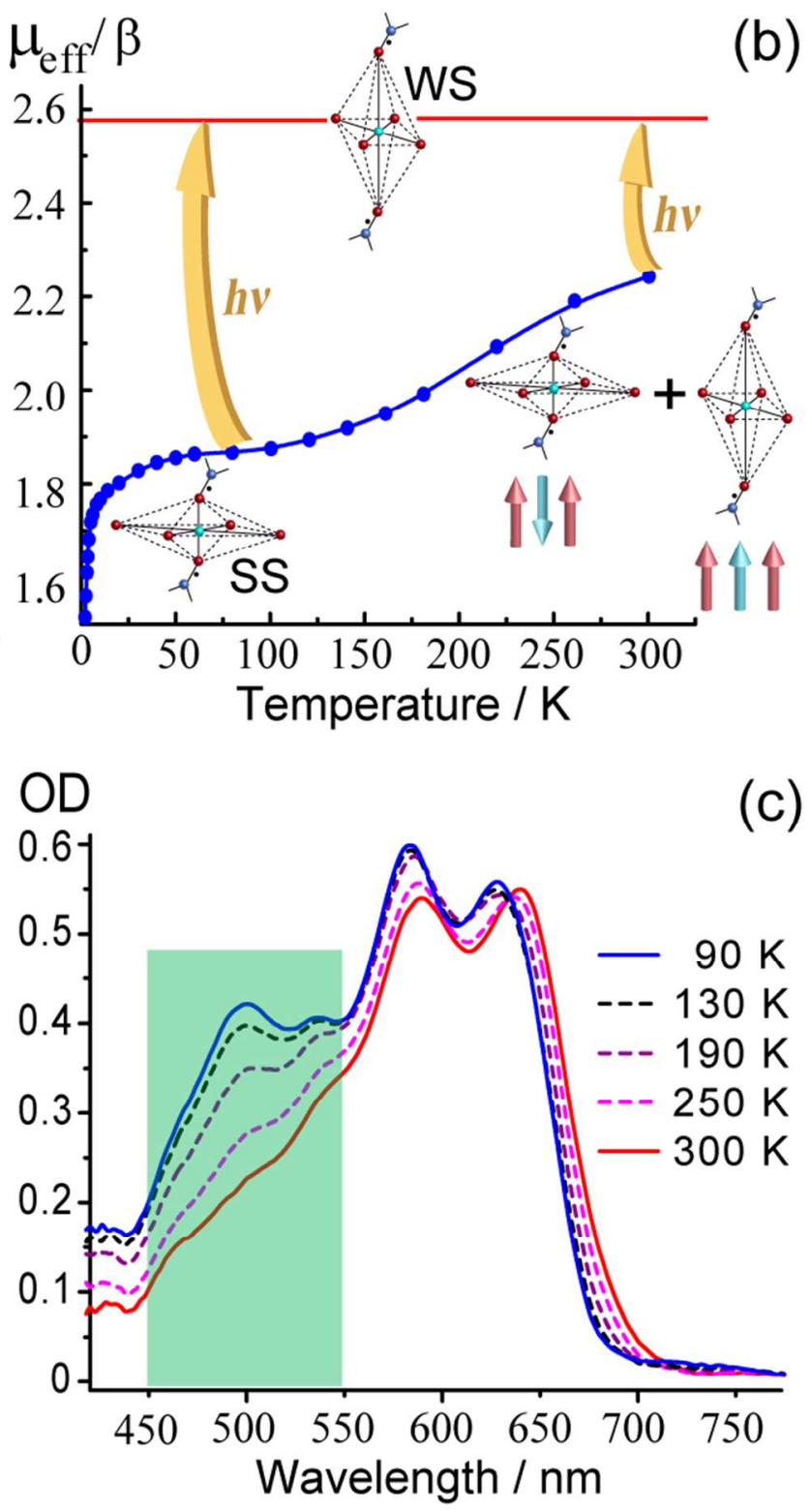

Figure 1

$80 \times 103 \mathrm{~mm}(300 \times 300 \mathrm{DPI})$ 

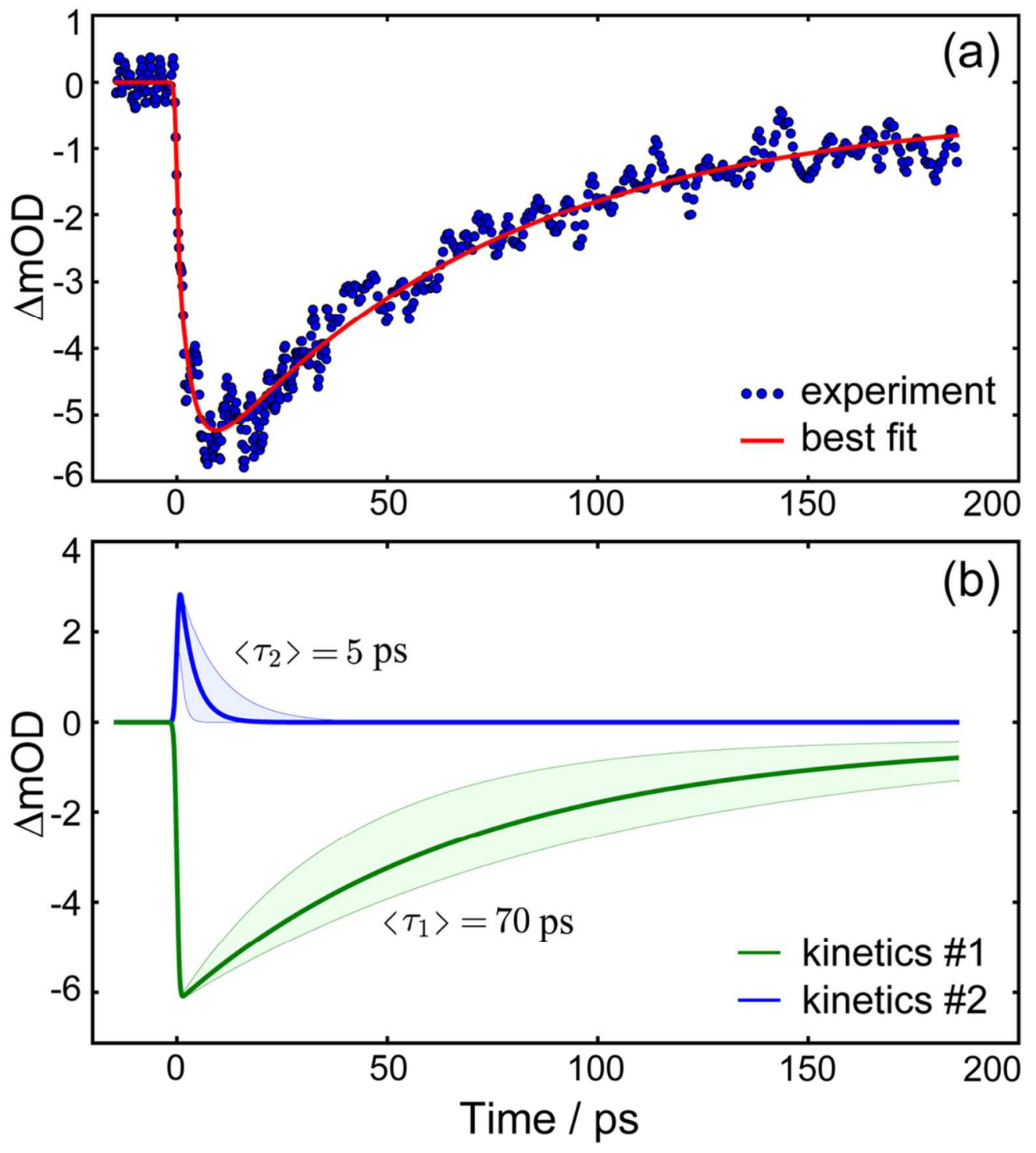

Figure 2

$91 \times 103 \mathrm{~mm}(300 \times 300 \mathrm{DPI})$ 

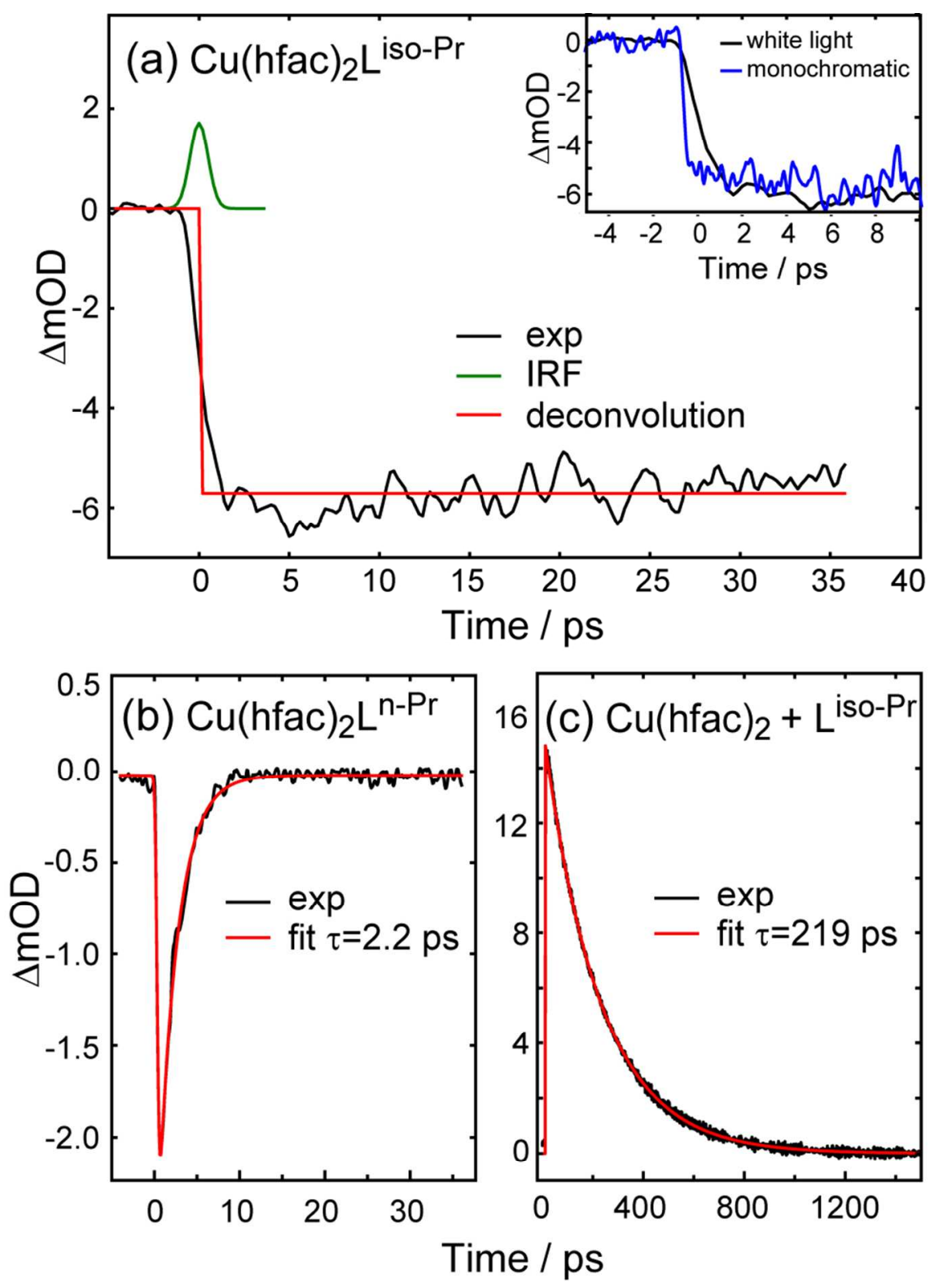

Figure 3

$82 \times 113 \mathrm{~mm}(300 \times 300 \mathrm{DPI})$ 
$\sim \frac{1}{2}$ ground $S S+\sim \frac{1}{2}$ ground WS
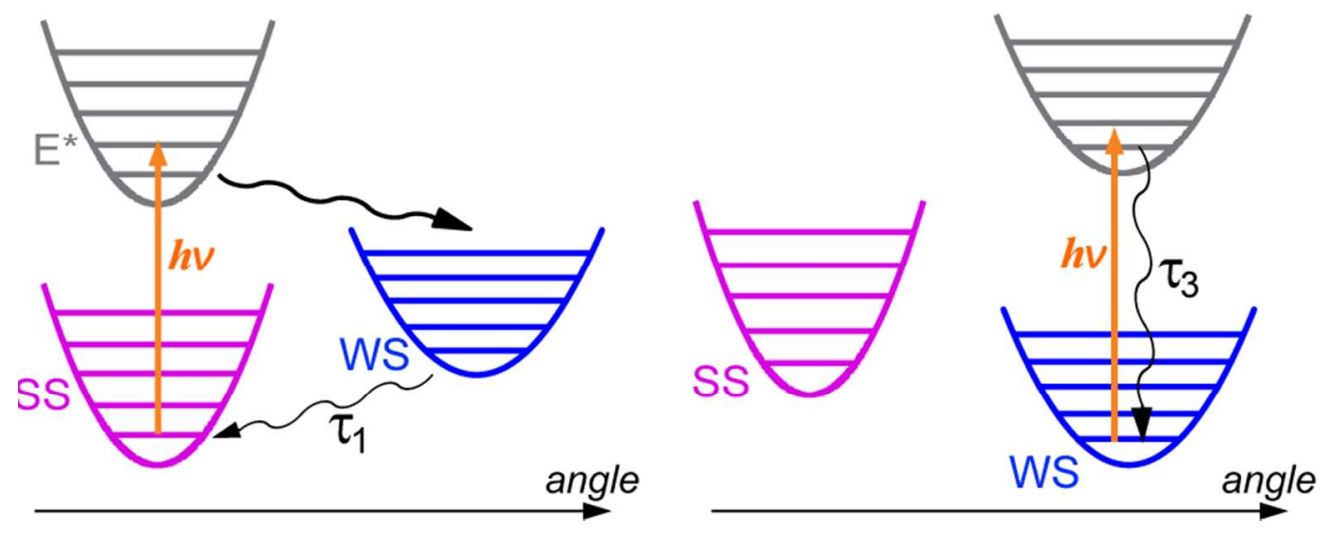

Figure 4

$82 \times 40 \mathrm{~mm}(300 \times 300$ DPI $)$ 